\title{
ISSR-derived Molecular Markers for Korean Wheat Cultivar Identification
}

\author{
Jae-Han Son ${ }^{1}$, Kyeong-Hoon Kim ${ }^{1}$, Sanghyun Shin ${ }^{1}$, Hag-Sin Kim ${ }^{1}$, Nam-Soo Kim², Jong-Nae Hyun ${ }^{1}$, Sang-In Shim ${ }^{3}$, \\ Choon-Ki Lee ${ }^{1}$, Kwang-Geun Park ${ }^{1}$, Chon-Sik Kang ${ }^{1 *}$ \\ ${ }^{1}$ Winter Cereal and Forage Crop Research Division, National Institute of Crop Science, Rural Development Administration, Iksan, \\ 570-080, Korea \\ ${ }^{2}$ Institute of Molecular and Bioscience, Kangwon National University, Chuncheon 200-701, Korea \\ ${ }^{3}$ Department of Agronomy, Gyenogsang National University, Jinju 660-701, Korea
}

\begin{abstract}
Inter simple sequence repeat (ISSR) is a technique that leads to the development of novel specific molecular markers and relationship analysis between species. In this study, 54 ISSRs were used to develop cultivar-specific DNA sequence characterized amplified regions (SCARs) for Korean wheat cultivars (Triticum aestivum). Using nine of 54 UBC ISSR primers, 16 cultivar-specific fragments were detected among 32 wheat cultivars. Of the 16 primers, 10 successfully amplified targets in 32 cultivars and six novel cultivar-specific markers were finally selected. A total of 13 Korean wheat cultivars (O1, Dahong, Namhae, Jinpum, Anbaek, Jopoom, Jokyung, Sinmichal 1, Jeokjoong, Dajung, Goso and Joah) were classified by newly developed six SCAR markers. Cultivar-specific markers can be used not only for cultivar fingerprinting but also for marker-assisted selection in wheat breeding program.
\end{abstract}

Keywords Molecular marker, ISSR, SCAR, Wheat

\section{INTRODUCTION}

Triticum aestivum, also known as common wheat, is an important food crop worldwide (Zhang et al. 2012), consumed by more than $40 \%$ of the world's population and is produced in more than 6,000,000 tons annually (Gupta et al. 2008). High quality elite cultivars that can adapt to climate change play a crucial role in wheat production $(\mathrm{Zhu}$ et al. 2011). Common wheat is a hexaploid $(2 \mathrm{n}=6 \mathrm{x}=42)$ consisted of three distinct genomes A, B, and D which has seven pairs of chromosomes each genome (Gao et al. 2004). Although A, B and D genome are different, they are genetically related to each other. Both $\mathrm{A}$ and $\mathrm{D}$ genome are diploid in origin, but the origin of $B$ genome is not yet clearly confirmed (Gill et al. 1991). Wheat has very large genome size which has more $80 \%$ of the entire genome consisted with repeat sequences like simple sequence repeat (SSR) or retrotransposon elements (Brenchley et al.
2012). Genes of each genome has tripled because common wheat germ cytological division is similar to that of normal diploid. These features facilitated the large genome research. Molecular markers have been used as a starter, genetic evolution research, and diagnosis in many crops including wheat. Using DNA-based molecular markers allows accurate, easy and rapid cultivar identification compare with phenotypic analysis and field growth test in wheat breeding program (Zhu et al. 2011). In addition, DNAbased molecular markers have been used in multi-purpose tools in various fields like taxonomy, physiology, embryology, and genetic engineering.

Simple sequence repeats (SSRs) or microsatellites were introduced by Litt and Lutty (1989). SSRs are short repeated sequence motifs of 1 to $6 \mathrm{bp}$, present numerously in eukaryotic genomes including plant and animals (Tauz and Renz 1984). Although SSR markers have many advantages like easy to use and detect higher degree polymorphism,

Received July 10, 2013; Revised September 9, 2013; Accepted September 17, 2013; Published September 30, 2013

*Corresponding author Chon-Sik Kang, kcs1209@korea.kr, Tel: +82-63-840-2156, Fax: +82-63-840-2116 
SSRs in coding regions are less abundant than in intergenic regions. Moreover, the process of developing SSR markers are difficult and complex such as in selecting and sequencing clones containing putative SSR motifs for designing and testing the flanking primers (Gao et al. 2004). Inter simple sequence repeat (ISSR) markers were reported by Zietkiewicz et al. (1994) which are developed by utilizing repeated microsatellites primers to amplify inter-SSR DNA sequences. Various microsatellites anchored at 5' end or 3' end are useful for amplifying genomic DNA which increase primer's specificity in PCR reaction (Godwin et al. 1997). Unlike other PCR-based techniques, ISSR does not require any information about target sequence of SSR regions (Tsumura et al. 1996). Advantages of ISSR include relatively low cost, high polymorphisms, and good reproducibility. ISSRs are highly rigid marker for scoring ISSR analysis because the random amplified markers are spurious or homoplasious bands (Bussell et al. 2005; Park et al. 2009). Kojima et al. (1998) showed that ISSR markers with Random amplified polymorphic DNA (RAPD) were used to construct genetic linkage map in Einkorn wheat. ISSR analysis is useful for detecting genetic diversity ( $\mathrm{Li}$ and Ge 2001; Sica et al. 2005), and analyzing species relationship as well as marker-assisted selection (MAS) for molecular breeding in plant using a single primer composed of SSR (Hussain et al. 2000; Joshi et al. 2000; Pasakinskene et al. 2000). ISSR markers were also used for identification of abiotic stress like drought (Deshmukh et al. 2012). In addition, SSR and ISSRs markers are useful for cultivar identification (Crespel et al. 2009; Lu et al. 2009), specifically ISSR markers have been used for wheat cultivar identification (Nagaoka and Ogihara 1997) including others such as radish (Liu et al. 2008), lotus (Chen et al. 2008), and rose (Crespel et al. 2009).

In Korea, many kinds of wheat cultivars suitable for different baked products such as breads, cakes and cookies have been developed. Molecular markers are necessary tool to identify these Korean cultivars yet these remains to be investigated. In this study, we developed sequence characterization amplified region (SCAR) or sequence tagged site (STS) markers for identification of 32 Korean wheat cultivars based on specific alleles using ISSR technology.

\section{MATERIALS AND METHODS}

\section{Plant materials and DNA extraction}

Genomic DNAs were extracted from young leaves of 32 Korean wheat varieties using HiGene ${ }^{\mathrm{TM}}$ Genomic DNA Prep Kit (SolGent, Korea). They were chosen as major cultivars in Korea and representative species in the classification of wheat variety (Table 1).

\section{PCR amplification and cloning}

Information of nucleotide sequences of the primers for inter simple sequence repeat (ISSR) PCR amplification is indicated in Table 2. PCR amplification was performed with $40 \mathrm{ng}$ of template genomic DNA, $5 \mathrm{uM}$ of primer, 2.5 $\mathrm{mM}$ of dNTP, and 1 unit of i-star maxII DNA polymerase (Intron, Korea) and Prime Taq DNA Polymerase (GENET Bio., Korea). The PCR annealing condition used consists 35 cycles of $94^{\circ} \mathrm{C}$ for $30 \mathrm{sec}, 50^{\circ} \mathrm{C}$ for $30 \mathrm{sec}$ and $72^{\circ} \mathrm{C}$ for $1 \mathrm{~min}$. Amplified products were checked on 1.5\% agarose gel electrophoresis where specific bands (300 - 1,000 bp) were eluted from the gel. The eluted DNA fragments were ligated into pGEM-T vector (Promega, USA), and cloned into DH5a competent Escherichia coli cells. Plasmid DNA were sent to Xenotech Inc., Korea for sequencing with the primer pairs M13 forward and SP6 using a PRISM3700 automatic DNA sequencer (ABI Inc.).

\section{Sequence analysis, primer design and re-amplification}

The sequence-analyzed DNA fragment length was determined from 300 to $1,000 \mathrm{bp}$. These fragments were included in wheat species (Fig. 1). The sequence information which was used to design the SCAR primers using primer3 (version 0.4.0, http://frodo.wi.mit.edu/) was confirmed in GenBank (NCBI, http://www.ncbi.nlm.nih.gov). Designed primers were tested for classification of Korean wheat varieties. PCR reaction was performed with $40 \mathrm{ng}$ of genomic DNA, $200 \mathrm{uM}$ of each dNTP, 1X reaction buffer and $1 \mathrm{U}$ i-star maxII DNA polymerase (Intron, Korea) in a total volume of $25 \mathrm{ul}$. PCR conditions include initial denaturation at $94^{\circ} \mathrm{C}$ for 3 min followed by 35 cycles of $94^{\circ} \mathrm{C}$ for $30 \mathrm{sec}, 50^{\circ} \mathrm{C}$ for $30,72^{\circ} \mathrm{C}$ for $1 \mathrm{~min}$ and the final extension of $72^{\circ} \mathrm{C}$ for $5 \mathrm{~min}$. The amplified DNA fragments were confirmed on $1.2 \%$ agarose gel electrophoresis. 
Table 1. The 32 Korean wheat cultivars used in this study and information of PCR amplification patterns.

\begin{tabular}{|c|c|c|c|c|c|c|c|}
\hline \multirow{2}{*}{ No. } & \multirow{2}{*}{ Variety } & \multicolumn{6}{|c|}{ SCAR marker name } \\
\hline & & $812-1$ & $812-4$ & $816-1$ & $816-2$ & $808 \mathrm{R}$ & $808 \mathrm{~A}$ \\
\hline 1 & $\mathrm{Ol}$ & + & + & - & + & - & - \\
\hline 2 & Geuru & - & - & - & - & + & + \\
\hline 3 & Dahong & + & - & - & + & - & - \\
\hline 4 & Chungkye & - & - & + & - & + & + \\
\hline 5 & Eunpa & - & - & - & + & + & + \\
\hline 6 & Tapdong & - & - & - & + & - & - \\
\hline 7 & Namhae & + & - & + & + & - & - \\
\hline 8 & Uri & - & - & - & - & + & + \\
\hline 9 & Olgeuru & - & + & - & - & + & + \\
\hline 10 & Alchan & - & - & - & - & + & + \\
\hline 11 & Gobun & - & + & + & + & + & + \\
\hline 12 & Keumkang & - & - & - & - & - & + \\
\hline 13 & Seodun & - & - & + & + & + & + \\
\hline 14 & Saeol & - & - & - & - & + & + \\
\hline 15 & Jinpoom & + & + & - & - & + & + \\
\hline 16 & Milsung & - & - & + & + & + & + \\
\hline 17 & Joeun & - & - & - & + & + & + \\
\hline 18 & Anbaek & + & - & - & - & + & + \\
\hline 19 & Jopoom & + & + & - & + & + & + \\
\hline 20 & Sinmichal & - & - & - & - & + & + \\
\hline 21 & Jonong & - & - & - & - & + & + \\
\hline 22 & Jokyung & + & + & - & - & - & + \\
\hline 23 & Younbaek & - & - & - & - & - & - \\
\hline 24 & Sinmichal 1 & + & + & - & - & - & - \\
\hline 25 & Baekjung & - & - & - & - & - & + \\
\hline 26 & Jeokjoong & + & - & - & - & - & + \\
\hline 27 & Sugang & - & - & - & - & + & + \\
\hline 28 & Hanbaek & - & - & + & + & - & - \\
\hline 29 & Suan & - & - & - & - & + & + \\
\hline 30 & Dajoon & + & + & - & - & + & + \\
\hline 31 & Goso & + & - & - & - & + & + \\
\hline 32 & Joa & + & + & - & - & + & + \\
\hline
\end{tabular}

* The + indicates amplified bands and - is absence

\section{RESULTS AND DISCUSSION}

\section{ISSR amplifications}

We have surveyed 54 ISSR primers for amplification using 32 Korean wheat cultivars, 14 of which showed consistent amplification and multiple polymorphism containing specific bands (Fig. 1). Other primers showing monomorphic banding pattern were not selected for further experiments in this study. ISSR primer UBC849 was profiled for identification of eight wheat cultivars in China wherein six different bands were amplified (Zhu et al.
2011), but when tested in Korean wheat cultivars there was no polymorphism detected UBC811 (Fig. 1). Although ISSR primer has been used for genetic linkage map in Einkorn wheat (Kojima et al. 1998), it was not used in this study because it failed to amplify the target allele. The 14 primers showing consistent and polymorphic amplification were consisted of all 3'-end anchoring (Fig. 1; Table 2). The number of amplified products varied from 1 to 8 with sizes that range from 200 to $1,000 \mathrm{bp}$ depending on the primers and cultivars. The PCR reactions were carried out over three times in different thermocyclers (GeneAmp 
PCR System 9700, ABI, USA; Biometra, Germany) using different DNA polymerase (Prime Taq DNA Polymerase, GENET Bio, Korea; i-star maxII, Intron, Korea) to obtain reproducible results. Since many bands were detected, the specific bands were eluted from the agarose gel for the sequencing. Polymorphisms were observed not only among different species like Sumai3 (data not shown) but also among different 32 Korean wheat cultivars (Fig.1).

\section{Sequence analysis and designing the SCAR primers}

We eluted 16 different DNA fragments from the agarose gel and performed the sequencing process. The number of eluted bands was one each in UBC808, UBC815, UBC816, UBC823 and UBC840, two in UBC807, and three each in UBC812, UBC813, and UBC819 (Fig. 1). BLAST analysis, querying the Triticum sequences deposited at NCBI, confirmed that the ISSR fragments were real DNA fragments from Wheat species, and further analysis of these primer pairs is therefore likely. However, all of the sequences are not coded with any functional genes because ISSR amplifies genomic sequences between SSR loci or non-coding regions (Son et al. 2012). Hence, we designed the SCAR primers using primer3 input (Ver. 0.4.0) program from 16 analyzed DNA sequences based on ISSR amplicons. The primer length was fixed 20 to $24 \mathrm{bp}$ to increase primer specificity and efficiency.

\section{Application of SCAR markers to 32 Korean wheat cultivars}

The newly developed markers were tested for reliability in classifying Korean wheat varieties. A total of ten cultivar-specific primer pairs which did not amplify or have generated non-specific band were discarded. With this, we used the remaining six primer pairs as SCARs (Table 3) which successfully amplified target sequences in Korean wheat cultivars with sizes of the amplicons corresponded well to expected length in sequence analysis (Fig. 2). Six SCAR primer pairs are generated from UBC808, UBC812 and UBC816. We tested these primer pairs over three times using different DNA polymerase and
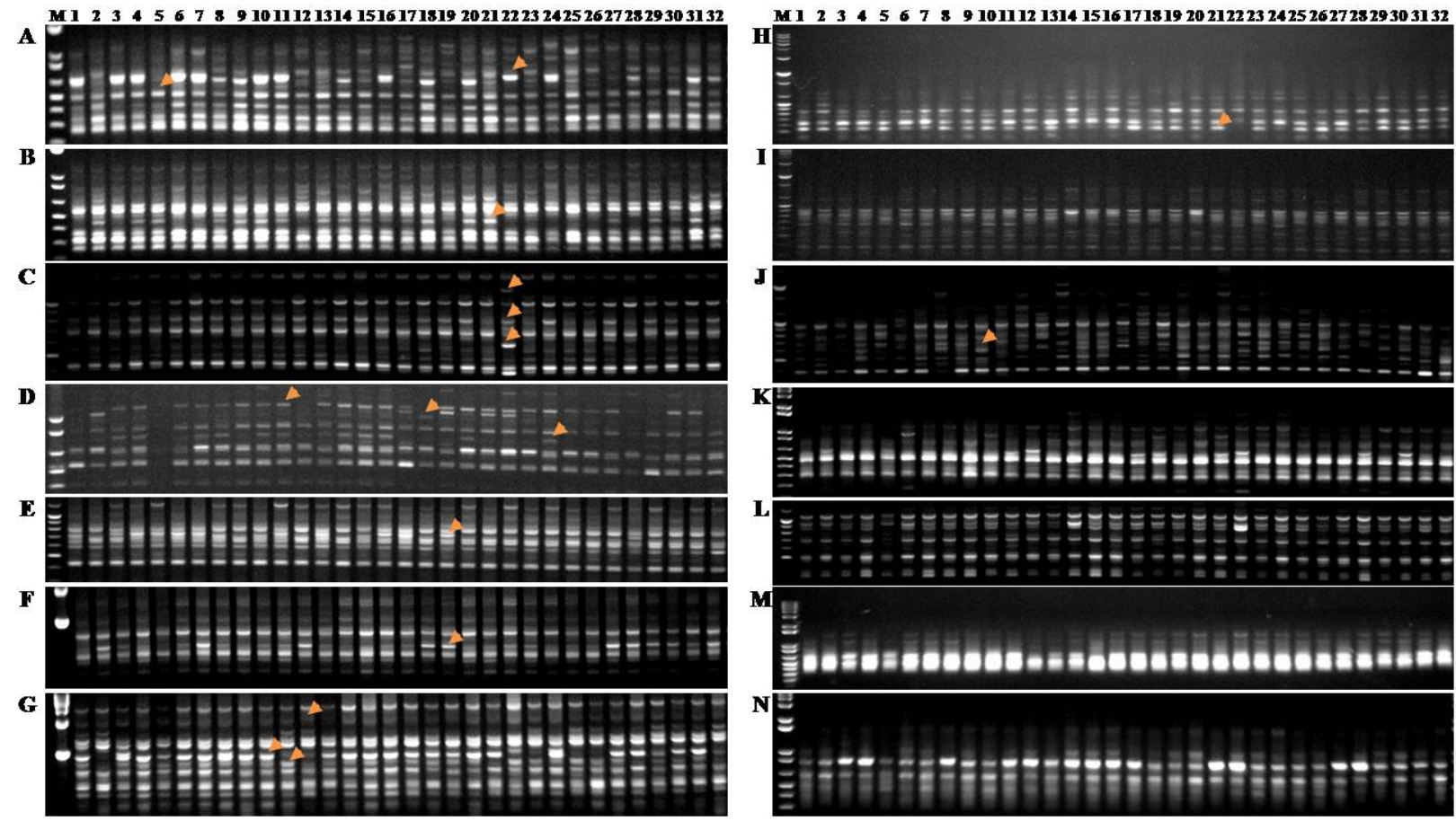

Fig. 1. ISSR profiles of 32 Korean wheat cultivars (1-32, Table 1). The amplified products were represented by the sizes ranging from 200 to $1,000 \mathrm{bp}$. The yellow Arrows indicate the eluted DNA fragment. A; UBC807, B; UBC808, C; UBC812, D; UBC813, E; UBC816, F; UBC815, G; UBC819, H; UBC823, I; UBC836, J; 840, K; 844, L; 846, M; UBC849, N; UBC880. 
PCR machines to validate the application of these SCARs for the identification of 32 Korean wheat cultivars. Although these markers have little disadvantage due to different annealing temperature in PCR condition, it did not affect the efficiency of the PCR assay. With these new marker combinations, a total of 13 out of 32 Korean wheat cultivars were identified as unique from each other (Fig. 2). These include Ol, Dahong, Chungkye, Tapdong, Namhae, Olgeuru, Gobun, Jopoom, Jokyoung, Younbaek, Sinmichal 1, Jeokjoong and Hanbaek.

Table 2. Sequence information of ISSR primers used in this study.

\begin{tabular}{cccccc}
\hline \hline No. & Primer & Sequence & No. & Primer & Sequence \\
\hline 1 & UBC801 & ATATATATATATATATT & 28 & UBC828 & TGTGTGTGTGTGTGTGA \\
2 & UBC802 & ATATATATATATATATG & 29 & UBC829 & TGTGTGTGTGTGTGTGG \\
3 & UBC803 & ATATATATATATATATC & 30 & UBC830 & TGTGTGTGTGTGTGTGC \\
4 & UBC804 & TATATATATATATATAA & 31 & UBC831 & ATATATATATATATATYA \\
5 & UBC805 & TATATATATATATATAC & 32 & UBC832 & ATATATATATATATATYC \\
6 & UBC806 & TATATATATATATATAG & 33 & UBC831 & ATATATATATATATATYA \\
7 & UBC807 & AGAGAGAGAGAGAGAGT & 34 & UBC832 & ATATATATATATATATYC \\
8 & UBC808 & AGAGAGAGAGAGAGAGC & 35 & UBC833 & ATATATATATATATATYG \\
9 & UBC809 & AGAGAGAGAGAGAGAGG & 36 & UBC834 & AGAGAGAGAGAGAGAGYT \\
10 & UBC810 & GAGAGAGAGAGAGAGAT & 37 & UBC835 & AGAGAGAGAGAGAGAGYC \\
11 & UBC811 & GAGAGAGAGAGAGAGAC & 38 & UBC836 & AGAGAGAGAGAGAGAGYA \\
12 & UBC812 & GAGAGAGAGAGAGAGAA & 39 & UBC837 & TATATATATATATATART \\
13 & UBC813 & CTCTCTCTCTCTCTCTT & 40 & UBC838 & TATATATATATATATARC \\
14 & UBC814 & CTCTCTCTCTCTCTCTA & 41 & UBC839 & TATATATATATATATARG \\
15 & UBC815 & CTCTCTCTCTCTCTCTG & 42 & UBC840 & GAGAGAGAGAGAGAGAYT \\
16 & UBC816 & CACACACACACACACAT & 43 & UBC841 & GAGAGAGAGAGAGAGAYC \\
17 & UBC817 & CACACACACACACACAA & 44 & UBC842 & GAGAGAGAGAGAGAGAYG \\
18 & UBC818 & CACACACACACACACAG & 45 & UBC843 & CTCTCTCTCTCTCTCTRA \\
19 & UBC819 & GTGTGTGTGTGTGTGTA & 46 & UBC844 & CTCTCTCTCTCTCTCTRC \\
20 & UBC820 & GTGTGTGTGTGTGTGTC & 47 & UBC845 & CTCTCTCTCTCTCTCTRG \\
21 & UBC821 & GTGTGTGTGTGTGTGTT & 48 & UBC846 & CACACACACACACACART \\
22 & UBC822 & TCTCTCTCTCTCTCTCA & 49 & UBC847 & CACACACACACACACARC \\
23 & UBC823 & TCTCTCTCTCTCTCTCC & 50 & UBC848 & CACACACACACACACARG \\
24 & UBC824 & TCTCTCTCTCTCTCTCG & 51 & UBC849 & GTGTGTGTGTGTGTGTYA \\
25 & UBC825 & ACACACACACACACACT & 52 & UBC850 & GTGTGTGTGTGTGTGTYC \\
26 & UBC826 & ACACACACACACACACC & 53 & UBC876 & GATAGATAGACAGACA \\
27 & UBC827 & ACACACACACACACACG & 54 & UBC880 & GGAGAGGAGAGGAGA \\
\hline
\end{tabular}

* $\mathrm{Y}$ and $\mathrm{R}$ are single letter abbreviation for mixed base positions. $\mathrm{Y}$ is presenting $\mathrm{C}$ or $\mathrm{T}, \mathrm{R}$ is presenting $\mathrm{A}$ or $\mathrm{G}$. The red letters indicate the selected UBC primers for eluting specific bands.

Table 3. The PCR condition information of six novel SCAR markers for the identification of 32 Korean wheat cultivars.

\begin{tabular}{|c|c|c|c|c|c|}
\hline $\begin{array}{c}\text { Marker } \\
\text { name }\end{array}$ & Forward sequences & Reverse sequences & $\begin{array}{c}\text { Annealing } \\
\text { temperature } \\
\left({ }^{\circ} \mathrm{C}\right)\end{array}$ & $\begin{array}{l}\text { Product } \\
\text { size } \\
\text { (bp) } \\
\end{array}$ & $\begin{array}{c}\text { Number of } \\
\text { Polymorphic } \\
\text { band }\end{array}$ \\
\hline $812-1$ & AAGAAGAAAAAGAAAGAGAGTTGAG & GTTGTGTTTTTATTTGTTTTTGAC & 55 & 359 & 1 \\
\hline $812-4$ & GCCGAGATTAAATTTGTTACTACT & AACATTTATGTTTGGTAAATTGAC & 55 & 312 & 1 \\
\hline $816-1$ & TGCTGAGGGCATATCTCAACA & GTGTTGCACGACGCTGTACT & 58 & 682 & 1 \\
\hline $816-2$ & TGCTGAGGGCATATCTCAACG & GTGTTGCACGACGCTGTACT & 58 & 682 & 1 \\
\hline $808 \mathrm{R}$ & GGCTTACTACCTACACTTGACC & GCAACAACAАCСТTCTCCСАAT & 58 & 392 & 1 \\
\hline $808 \mathrm{~A}$ & GGCTTACTACCTACACTTGACC & ААСААССТТСТСССААТССССТ & 58 & 392 & 1 \\
\hline
\end{tabular}


Unlike the other 12 cultivars, Younbaek was identified distinctly from the others because of unamplified reactions from all primer sets. The 812-1 SCAR marker was amplified in 12 cultivars, Ol, Dahong, Namhae, Jinpum, Anbaek, Jopoom, Jokyung, Sinmichal 1, Jeokjoong, Dajung, Goso and Joah. Interestingly, no coded functions has been designated yet to this gene marker in Triticum. However, some of these cultivars have been reported to exhibit traits such as Jeokjoong which is known to have moderate resistance to Fusarium and is used for making noodle (Park et al. 2008), Baegjoong and Joah which are resistant to pre-harvest sprouting, and Goso which is very useful for making cookie as well as it has resistance to pre-harvest sprouting like Baegjoong, Joa and Sugang (Park et al. 2009). Similar to $812-1$, the $812-4$ is functionally noncoded gene marker which was specifically amplified in nine Korean wheat cultivars (Ol, Olgeuru, Gobun, Jopoom, Jokyung, Sinmichal 1, Dajung and Goso). Additionally, the number of Korean wheat cultivars with amplifications were six for 816-1, 11 for 816-2, 21 for 808R, and 25 for $808 \mathrm{~A}$ primer. The complete detail of the cultivar and primer pair combination with amplifications is shown in Fig. 2.

Both $816-1$ and $816-2$ are allele-specific primers. A nucleotide of 3'- end is different, 816-1 is A ( $\mathrm{T}$ allelespecific primer) and 816-2 is $\mathrm{T}$ (A allele-specific primer). With this, Chungkye contains $\mathrm{T}$ allele because it showed amplification with 816-1but not with 816-2 primer. On the otherhand, Ol, Dahong, Eunpa, Tapdong, Joeun and Jopoom have A allele while Namhae, Gobun, Seodun, Milseong, Jeokjoong, have both $\mathrm{T}$ and $\mathrm{A}$ alleles.

Since19 Korean wheat cultivars were not clearly identified and classified by the six primer sets, we planned to proceed with both amplified fragment length polymorphism (AFLP) and transposon display (TD) techniques to detect more polymorphism. With this technique, we expect to classify
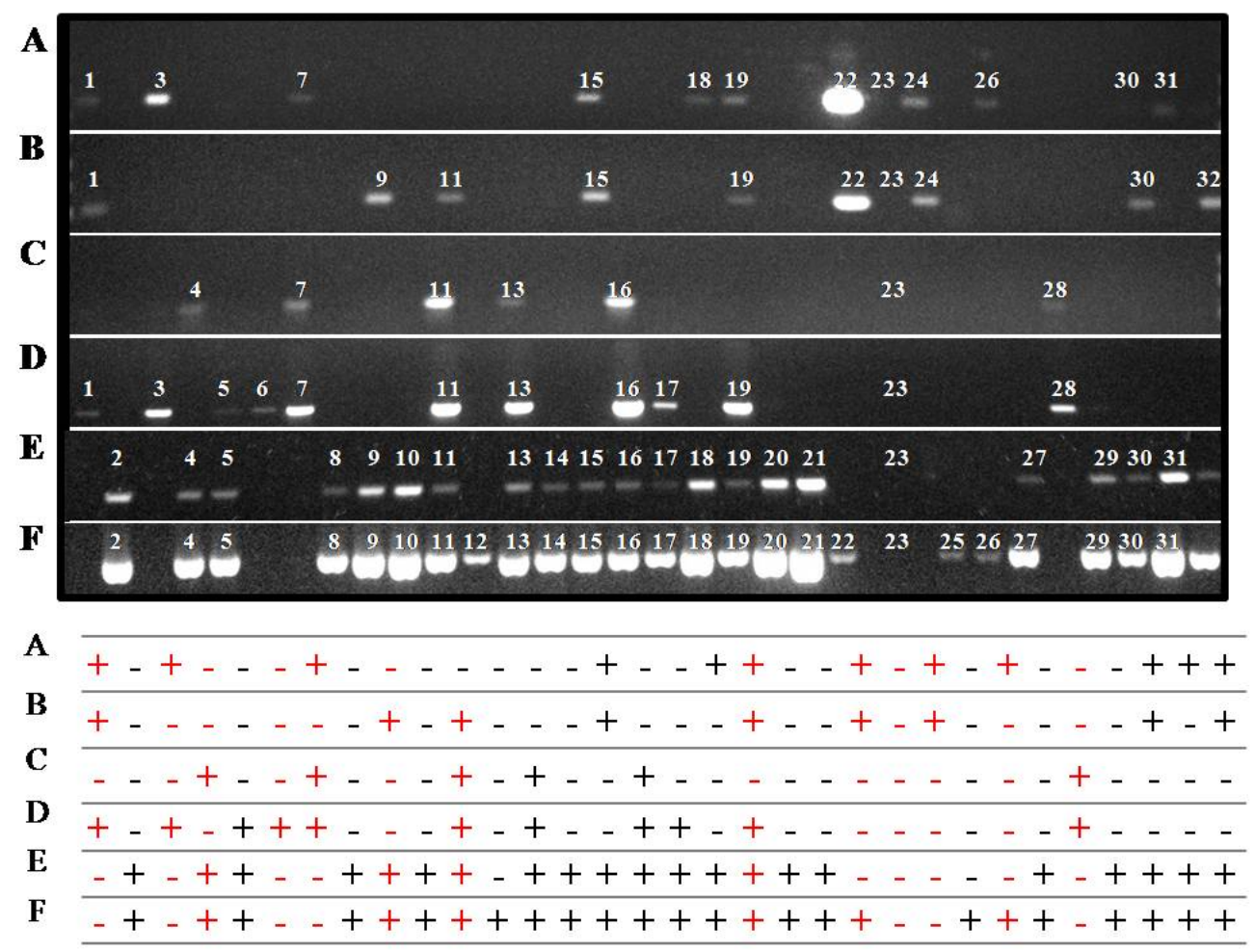

Fig. 2. The profiles of PCR amplified DNA fragments using developed SCAR markers in 32 Korean wheat cultivars. The + indicates amplified bands and - is absence. Red + indicated the distinguished 12 cultivars, 1; Ol, 3; Dahong, 4; Chungkye, 6; Tapdong, 7; Namhae, 9; Olguru, 11; Gobun, 19; Jopoom, 22; Jokyoung, 23; Younbaek, 24; Sinmichal 1, 26; Jeokjoong, 28; Hanbaek, by six novel markers combination. A; 812-1, B; 812-4, C; 816-1, D; 816-2, E; 808R and F; 808A. 
more cultivars using variable molecular markers in the future. Nonetheless in this study we were able to identify 13 out of 32 Korean wheat cultivars using the 6 primer pairs. The newly developed cultivar-specific SCAR markers can be used not only for cultivar fingerprinting but also for marker-assisted selection and inter-specific hybridization to combine important traits in the wheat breeding program (Burton 1992; Brilman 2001). This technique also saves time and money by performing only one PCR reaction.

\section{CONCLUSION}

Inter simple sequence repeat (ISSR) is a useful technique to analyze the relationship between species and to develop specific molecular markers without the need of target sequence information. In this study, we used ISSR primers to develop cultivar-specific DNA SCARs for Korean wheat cultivars. Six novel cultivar-specific markers (designated 812-1, 812-4, 816-1, 816-2, 808R, and 808A) were developed to identify 13 cultivars using 54 ISSR primers. A total of 13 cultivars were identified as unique based on specific alleles amplified which include Ol, Dahong, Namhae, Jinpum, Anbaek, Jopoom, Jokyung, Sinmichal 1, Jeokjoong, Dajung, Goso and Joah. Of which, Jokyung and Goso are few of the major cultivated wheat cultivars together with Keumkang in Korea. Cultivar-specific markers can be used not only for cultivar fingerprinting but also for marker-assisted selection in wheat breeding program. Furthermore, because ISSRs are based on universal repeat motifs in the genome, ISSRs can be used in molecular bio-techniques for development of novel marker and species relationship analysis in plants.

\section{ACKNOWLEDGMENT}

This study was supported by 2013 Postdoctoral Fellowship Program of National Institute of Crop Science, Rural Development Administration, Republic of Korea.

\section{REFERENCES}

Brenchley R, Spannag M, Pfeifer M, Barker GLA, D’Amore R, Allen AM, McKenzie N, Kramer M, Kerhornou A, Bolser D, Kay S, Waite D, Trick M, Bancroft I, Gu Y, Huo N, Luo MC, Sehgal S, Gill B, Kianian S, Anderson O, Kersey P, Dvorak J, McCombie WR, Hall A, Mayer KFX, Edwards KJ, Bevan MW, Hall N. 2012. Analysis of the bread wheat genome using whole genome shotgun sequencing. Nature 491: 705-710.

Brilman LA. 2001. Colonial bentgrass: An option for fairways. Golf Course Manage. 69(1): 55-60.

Bussell JD, Waycott M, Chappill JA. 2005. Arbitrarily amplified DNA markers as characters for phylogenetic inference. Perspect. Plant Ecol. Evol. Systemat. 31: 3-26.

Crespel L, Pernet A, Bris ML, Gudin S, Oyant LHS. 2009. Application of ISSRs for cultivar identification and assessment of genetic relationships in rose. Plant Breed. 128: 501-506.

Burton GW. 1992. Breeding improved turfgrass, p. 759-775. In: D.V. Waddington et al. (ed.). Turfgrass. ASA, CSSA, and SSSA, Madison, WI.

Chen YY, Zhou RC, Lin XD, Wu KQ, Qian X, Huang SZ. 2008. ISSR analysis of genetic diversity in sacred lotus cultivars. Aquat. Bot. 89: 311-316.

Deshmukh R, Tomar NS, Tripathi N, Tiwari S. 2012. Identification of RAPD and ISSR markers for drought tolerance in wheat (Triticum aestivum L.). Physiol. Mol. Biol. Plants 18: 101-104.

Gao LF, Jing RL, Huo NX, Li Y, Li XP, Zhou RH, Chang XP, Tang JF, Ma ZY, Jia JZ. 2004. One hundred and one new microsatellited loci derived from ESTs (EST-SSRs) in bread wheat. Theor. Appl. Genet. 108: 1392-1400.

Gill KS, Lubbers EL, Gill BS, Raupp WJ, Cox TS. 1991. A genetic linkage map of Triticum tauschii (DD) and its relationship to the $\mathrm{D}$ genome of bread wheat (AABBDD). Genome 34: 362-374.

Godwin ID, Aitken EAB, Smith LW. 1997. Application of inter simple sequence repeat markers to plant genetics. Electrophoresis 18: 1524-1528.

Gupta PK, Mir RR, Mohan A, Kumar J. 2008. Wheat genomics: present status and future prospects. Int. J. Plant Genomics 2008: 896-451.

Hussain AJ, Gupta V, Ali J, Ranjekar PK, Aiddiq EA. 2000. Physiological characterization, genetics and molecular mapping of a new source of temperature sensitive genetic 
male sterility in rice. 4th International Rice Genetics Symposium. 22-27 October 2000, IRRI, Philippines, Abstract p.95.

Joshi SP, Gupta VS, Aggrawal PK, Ranjekar K, Brar DS. 2000. Genetic diversity and phylogenetic relationship as revealed by inter-simple-sequence repeat (ISSR) polymorphism in the genus Oryza. Theor. Appl. Genet. 100: 1311-1320.

Kojima T, Nagaoka T, Noda K, Ogihara Y. 1998. Genetic linkage map of ISSR and RAPD markers in Einkorn wheat in relation to that of RFLP markers. Theor. Appl. Genet. 96: 37-45.

Li A, Ge S. 2001. Genetic variation and clonal diversity of Psammo chloavillosa (Poacea) detected by ISSR markers. Ann. Bot. 87: 585-590.

Litt M, Luty JA. 1989. A hyper variable microsatellite revealed by in vitro amplification of a dinucleotide repeat within the cardiac muscle actin gene. Am. J. Hum. Genet. 44(3): 397-401.

Liu LW, Zhao LP, Gong YQ, Wang MX, Chen LM, Yang JL, Wang Y, Yu FM, Wang LZ. 2008. DNA fingerprinting and genetic diversity analysis of late-bolting radish cultivars with RAPD, ISSR and SRAP markers. Sci. Hortic. 116: 240-247.

Lu XJ, Liu LW, Gong YQ, Zhao LP, Song XY, Zhu XW. 2009. Cultivar identification and genetic diversity analysis of broccoli and its related species with RAPD and ISSR markers. Sci. Hortic. 122: 645-648.

Nagaoka T, Ogihara Y. 1997. Applicability of inter-simple sequence repeat polymorphisms in wheat for use as DNA markers in comparison to RFLP and RAPD markers. Theor. Appl. Genet. 94: 597-602.

Park CS, Heo HY, Kang MS, Lee CK, Park KG, Park JC, Kim HS, Kim HS, Hwang JJ, Cheong YK, Kim JG. 2008. A new white wheat variety, "Jeokjoong" with high yield, good noodle quality and moderate to Scab. Korean J. Breed. Sci. 41(3): 308-313.

Park CS, Heo HY, Kang MS, Kim HS, Park HH, Park JC, Kang CS, Kim HS, Cheong YK, Park KH. 2009. A new wheat variety, "Sukang" with good noodle quality, resistant to winter hardiness and pre-harvest sprouting. Korean J. Breed. Sci. 41(1): 44-50.

Park YJ, Lee JK, Kim NS. 2009. Simple Sequence Repeat Polymorphisms (SSRPs) for evaluation of molecular diversity and germplasm classification of minor crops. Molecules 14: 4546-4569.

Pasakinskiene I, Griffths CM, Bettany AJE, Paplauskiene V, Humphrey MW. 2000. Anchored simple-sequence repeats as primers to generate species-specific DNA markers in Loliumand festuca grasses. Theor. Appl. Genet. 100: 384-390.

Sica M, Gamba G, Montieri S, Gaudio L, Aceto S. 2005. ISSR markers show differentiation among Italian populations of Asparagus acutifoliusL. BMC Genet. 6:17, doi: 10.1186/1471-2156-6-17.

Son JH, Park KC, Lee SI, Kim JH, Kim NS. 2012. Species Relationships among Allium Species by ISSR Analysis. Hort. Environ. Biotechnol. 53(3): 256-262.

Tautz D, Renz M. 1984. Simple sequences are ubiquitous repetitive components of eukaryotic genomes. Nucl. Acids Res. 12: 129-128.

Tsumura Y, Ohba K, Strauss SH. 1996. Diversity and inheritance of inter-simple sequence repeat polymorphisms in Douglas-fir (Pseudotsu gamenziesii) and sugi (Cryptomeria japonica). Theor. Appl. Genet. 92: 40-45.

Zhang D, Hao C, Wang L, Zhang X. 2012. Identifying loci influencing grain number by microsatellite screening in bread wheat (Triticum aestivum L.) Planta DOI 10.1007/ s00425-012-1708-9.

Zhu Y, Hu J, Han R, Wang Y, Zhu S. 2011. Fingerprinting and identification of closely related wheat (Triticum aestivum L.) cultivars using ISSR and fluorescencelabeled TP-M13-SSR markers. Australian Journal of Crop Sci. 5(7): 846-850.

Ziekiewicz E, Rafalski A, Labuda D. 1994. Genome fingerprinting by simple sequence repeat (SSR)-anchored polymerase chain reaction amplification. Genomics 20: 176-183. 